\title{
Carcinoma escamoso de conducto auditivo externo: Reporte de 3 casos
}

\section{Squamous cell carcinoma of the external auditory canal: Report of three cases}

\author{
Olenka Alcas A', Miguel A. Salazar L
}

\begin{abstract}
RESUMEN
El carcinoma escamoso de conducto auditivo externo es poco frecuente. La sintomatología puede semejar una otitis externa u otitis media crónica, lo que puede retrasar el diagnóstico. La falta de un sistema de clasificación y el número limitados de casos hace difícil la elaboración de guías de tratamiento. Se describe una serie de casos de esta neoplasia, así como una revisión de la literatura actual.
\end{abstract}

Palabras clave: Conducto auditivo externo, carcinoma escamoso, hueso temporal.

\begin{abstract}
Squamous cell carcinoma of the external auditory canal is rare. The symptoms may resemble an external otitis or chronic otitis media, which can delay diagnosis. The lack of a classification system and the limited number of cases makes it difficult the development of treatment guidelines. We present a case series of this neoplasia, as well as a review of the literature.
\end{abstract}

Key words: External auditory canal, squamous carcinoma, temporal bone.

\section{INTRODUCCIÓN}

El cáncer de canal auditivo externo es una patología poco frecuente, representando el $0,2 \%$ de todos los cánceres de cabeza y cuello. El $4 \%$ de los cánceres de oído externo están confinados al conducto auditivo externo; siendo la incidencia de carcinoma de conducto auditivo externo (CAE) entre uno a seis por millón de habitantes, y la prevalencia uno por millón de habitantes. Se presenta en la quinta y sexta década de vida, con ligera predominancia masculina'.

La sintomatología de estos tumores se caracteriza por otalgia, otorrea, hipoacusia y tinnitus,

Servicio de Otorrinolaringología, Hospital Edgardo Rebagliati Martins. Lima, Perú. 
similar a una otitis externa u otitis media crónica, lo cual puede retrasar su diagnóstico. No obstante, cuando un paciente no responde al tratamiento, debe considerarse otros diagnósticos diferenciales y plantearse una biopsia. Además, puede presentarse parálisis facial que plantea extensión fuera del canal auditivo; mientras que las adenopatías de neoplasias primarias de hueso temporal pueden ser encontradas en menos de $17 \%$ de pacientes ${ }^{2,3}$.

El tipo histológico más frecuente es carcinoma escamoso, siendo su diagnóstico mediante biopsia histopatológica. Otros tipos histológicos incluyen carcinoma basocelular, melanoma maligno, carcinoma de células de Merkel, angiosarcoma, carcinoma anexial que incluye adenocarcinoma ceruminoso y carcinoma adenoide quístico, y linfoma'.

El carcinoma escamoso de conducto auditivo externo puede ser localmente agresivo debido a que el hueso temporal no actúa como una barrera efectiva de contención, pudiendo diseminar la neoplasia por difusión microscópica a través de canales y vasos intraóseos y nervios. Adicionalmente, la sutura petroescamosa, fisuras de Santorini, foramen de Huschke, foramen estilomastoideo, ventana redonda y oval, celdas mastoideas y la membrana timpánica son vías de diseminación. Las placas óseas sobre estructuras como el bulbo yugular, carótida, tegmen, canal de Falopio y laberinto son delgadas y muy vulnerables a la erosión tumoral. Estos hallazgos pueden observarse con métodos de imágenes como tomografía y resonancia magnética, fundamentales en el estadiaje, terapia y pronóstico $0^{3,4}$.

\section{CASO CLÍNICOS}

Se realizó un estudio retrospectivo de 3 pacientes diagnosticados de carcinoma escamoso de conducto auditivo externo, en el servicio de otorrinolaringología. Las características clínicas y estadios se detallan en la Tabla 1, Figuras 1 y 2.

Todos los pacientes eran hombres mayores de 60 años de edad, y presentaron como síntomas comunes otalgia y otorrea que no cedía con antibióticos. No tenían antecedentes clínicos de interés. Todos fueron sometidos a TC y biopsia de la tumoración en conducto auditivo externo.

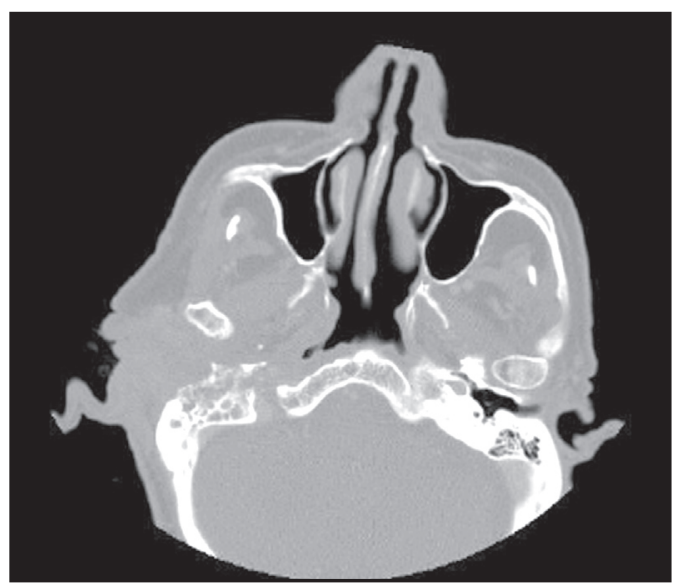

Figura 1. Tomografía de mastoides de caso 2. Proceso expansivo infiltrativo por neoplasia maligna en el conducto auditivo externo derecho, con obstrucción del conducto y otomastoiditis crónica derecha.

Tabla 1. Características clínicas, TNM y tratamiento de pacientes

\begin{tabular}{|c|c|c|c|c|c|c|c|c|c|c|}
\hline$\#$ & Sexo & Edad & Síntomas & PF & Duración & TNM & EC & $Q X$ & $\mathrm{RT} / \mathrm{QT}$ & Seguimiento \\
\hline 1 & M & 71 & $\begin{array}{l}\text { Otalgia, otorrea, } \\
\text { tinnitus }\end{array}$ & No & 1 aก̃o & T1NOMO & I & $\mathrm{L}$ & No & $\begin{array}{l}\text { Curado, } \\
\text { seguimiento } \\
\text { de } 2 \text { años }\end{array}$ \\
\hline 2 & M & 83 & $\begin{array}{l}\text { Otalgia, otorrea, } \\
\text { cefalea }\end{array}$ & $\mathrm{Si}$ & 2 años & T4NOMO & IV & - & RT & $\begin{array}{l}\text { *Se negó a Qx. } \\
\text { Tumor residual. } \\
\text { Tratamiento } \\
\text { paliativo actual. }\end{array}$ \\
\hline 3 & M & 68 & $\begin{array}{l}\text { Otalgia, otorrea, } \\
\text { prurito }\end{array}$ & No & 5 años & T2NOMO & $\|$ & $\mathrm{RL}$ & No & $\begin{array}{l}\text { Curado. } \\
\text { Seguimiento } 1 \text { año }\end{array}$ \\
\hline
\end{tabular}

PF: Parálisis facial, L: Local, RT: Radioterapia, QT: Quimioterapia, RL: Resección lateral de hueso temporal. 


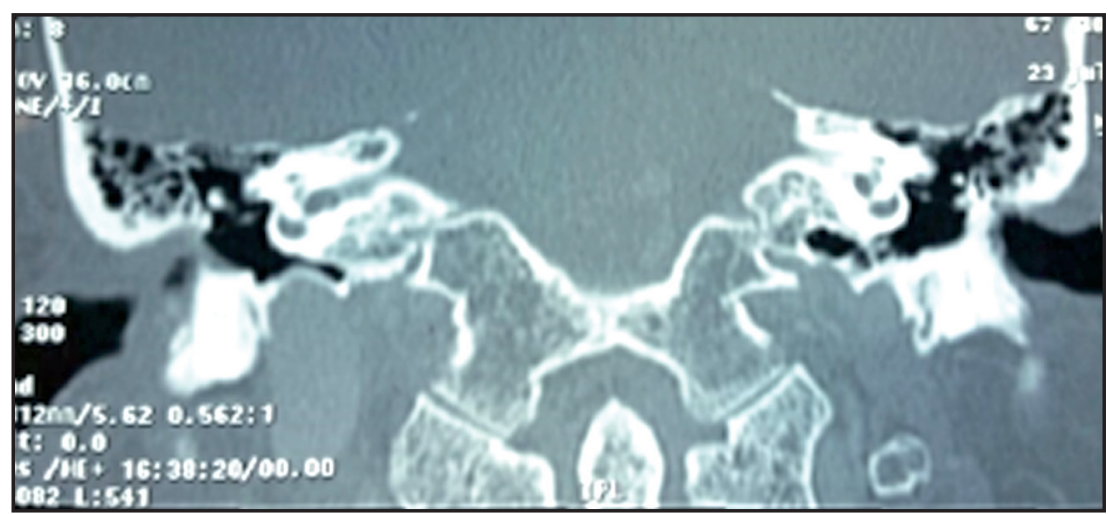

Figura 2. Tomografía de oído y mastoides de caso 3. Presencia de lesión con densidad de partes blandas que compromete el área membranosa del conducto auditivo externo derecho, sin compromiso de mastoides o caja timpánica.

\section{Caso clínico 1}

Hombre de 71 años, sin antecedentes de importancia, presentó otalgia, otorrea y acúfenos de 1 año de evolución, con un estadio I según la clasificación de Pittsburgh. La tomografía reveló una tumoración de 2,7 cm en conducto auditivo externo, que no erosionaba el conducto óseo ni comprometía membrana timpánica, oído medio 0 mastoides. El hallazgo operatorio incluyó una tumoración de aspecto granulomatoso que ocupaba $2 / 3$ internos del conducto auditivo externo, sin comprometer membrana timpánica. La resección fue local en bloque, permitiendo la visualización de la membrana timpánica. El resultado anatomopatológico posoperatorio de la pieza fue carcinoma escamoso bien diferenciado queratinizante infiltrante. No se reportó recidiva a los 2 años de seguimiento.

\section{Caso clínico 2}

Hombre de 83 años, presentó cefalea y parálisis facial derecha como síntoma agregado a la otalgia y otorrea, con un estadiaje IV. La biopsia fue carcinoma escamoso bien diferenciado queratinizante infiltrante con focos de necrosis. La tomografía reportó una tumoración expansiva infiltrativa de $2 \mathrm{~cm} \times 1,8 \mathrm{~cm}$ que obstruía el conducto con otomastoiditis crónica derecha, además de hacer contacto con espacio parotídeo en su borde superior. Inicialmente se le planteó tratamiento quirúrgico pero el paciente no aceptó. Se procedió a tratamiento con radioterapia 60 Gy en 30 dosis, tras lo cual queda con tumoración residual. En una nueva evaluación se consideró no tributario a cirugía o radioterapia, ésta última porque ya había tenido un ciclo reciente de radioterapia. Se le planteó quimioterapia, pero el paciente se negó a recibir tratamiento adicional. Actualmente, luego de 7 meses de diagnóstico, se encuentra con tratamiento paliativo.

\section{Caso clínico 3}

Hombre de 68 años, presentó 5 años de enfermedad, y fue catalogado como estadio II. La tomografía reportó lesión que comprometía el área membranosa del conducto auditivo externo, con erosión de parte ósea, sin compromiso de caja timpánica o parótida. El hallazgo operatorio mostró una tumoración irregular indurada dependiente de región posteroinferior del conducto auditivo externo derecho, con membrana timpánica y cadena osicular intacta. Se realizó una resección lateral de hueso temporal, que incluyó una mastoidectomía cerrada con apertura de receso facial. Se resecó el canal auditivo externo en bloque junto con la membrana timpánica, el martillo y yunque. La anatomía patológica concluyó carcinoma epidermoide medianamente diferenciado infiltrante no queratinizante con focos de necrosis. No hay signos de recidiva al año de seguimiento. 


\section{DISCUSIÓN}

El cáncer de hueso temporal no tiene un sistema de estadiaje reconocido por el American Joint Committee on Cancer (AJCC) o International Union Against Cancer (UICC), pero se ha establecido otros sistemas de clasificación. El más utilizado es el sistema de estadiaje de Pittsburgh, descrito en 1990 por Arriaga ${ }^{5}$ y modificado en 2000 por Moody $^{6}$, que permite predecir supervivencia (Tabla 2).

La diferenciación tumoral ha demostrado que tiene implicancia en la supervivencia. Los carcinomas escamosos pobremente diferenciados están asociados a una menor supervivencia comparados con los bien o moderadamente diferenciados ${ }^{7}$. Sin embargo, en lesiones de estadio IV, no se ha visto diferencias en la supervivencia asociado al grado de diferenciación ${ }^{8}$. En nuestros casos, la histología mostró patrones bien o moderadamente diferenciados, pudiendo asociarse a un periodo mayor de sobrevida.

El tratamiento óptimo de carcinoma escamoso de conducto auditivo externo es tópico de debate y controversia. No obstante, la cirugía con 0 sin radioterapia adyuvante es considerada el tratamiento estándar. El objetivo es la resección en bloque con márgenes quirúrgicos negativos, lo cual no siempre es posible en lesiones avanzadas. Los estadios I y || pueden ser tratados sólo con cirugía, reservando la radioterapia para rescate. En tumores T1 que están confinados a tejidos blandos, canal auditivo membranoso o cartilaginoso, se puede realizar escisión amplia que incluye piel y cartílago adyacente. No deben dejarse márgenes quirúrgicos positivos para radiación posoperatoria, debido al riesgo potencial de osteorradionecrosis, estenosis de canal y otitis externa crónica².

Tabla 2. Clasificación de la Universidad de Pittsburgh

\begin{tabular}{|c|c|}
\hline Sistema de clas & ón de la Universidad de Pittsburgh para carcinoma de canal auditivo, oído medio y hueso temporal \\
\hline Clasificació & \\
\hline $\mathrm{T} 1$ & Limitado al CAE sin erosión ósea o evidencia de compromiso de teiidos blandos \\
\hline T2 & Erosión ósea de canal auditivo externo limitado (no grosor total) o de tejido blando $(<0,5 \mathrm{~cm})$ \\
\hline T3 & $\begin{array}{l}\text { Tumor que erosiona hueso CAE (todo el grosor) con compromiso limitado }(<0,5 \mathrm{~cm}) \text { de tejido } \\
\text { blando o tumor que compromete oído medio y/o mastoides }\end{array}$ \\
\hline T4 & $\begin{array}{l}\text { Tumor que erosiona cóclea, ápex petroso, pared medial de oído medio, canal carotídeo, foramen } \\
\text { yugular o dura, o con compromiso extenso de tejidos blandos }(>0,5 \mathrm{~cm}), 0 \text { evidencia de paresia } \\
\text { facial }\end{array}$ \\
\hline N & \\
\hline NO & No metástasis ganglionar regional \\
\hline N1 & Metástasis ganglionar regional única $<3 \mathrm{~cm}$ \\
\hline N2a & Metástasis ganglionar ipsilateral única entre 3-6 cm \\
\hline $\mathrm{N} 2 \mathrm{~b}$ & Metástasis ganglionar ipsilateral múltiple $<6 \mathrm{~cm}$ \\
\hline $\mathrm{N} 2 \mathrm{C}$ & Metástasis ganglionar contralateral \\
\hline N3 & Metástasis ganglionar $>6 \mathrm{~cm}$ \\
\hline M & Metástasis a distancia \\
\hline Estadios & \\
\hline Estadio I & T1 No \\
\hline Estadio II & T2 No \\
\hline Estadio III & T3 No \\
\hline Estadio IV & T4 N0, T1-4 N1-3, M1 \\
\hline
\end{tabular}

CAE: Conducto Auditivo Externo. Adaptado de . 
En los tumores T1 del canal óseo o T2 se prefiere resección ósea temporal lateral. Si la tumoración alcanzó oído medio, la resección lateral de hueso temporal no es la opción ideal. El compromiso más allá de la membrana timpánica hacia cóclea o laberinto requiere una resección de hueso temporal subtotal; mientras la extensión hacia ápex petroso, una resección de hueso temporal total, una ocurrencia más rara. En estadios más avanzados, la extensión del tumor demanda un manejo multidisciplinario; mientras que si hay compromiso carotídeo o encefálico, el tratamiento quirúrgico no es de elección ${ }^{2,8}$.

La radioterapia está indicada en tumores T3 y $\mathrm{T} 4$, y no debe ser utilizada como terapia definitiva excepto en aquellos pacientes que tienen contraindicación quirúrgica. Usualmente se utiliza 54-60 Gy tanto al sitio primario y al cuello en 30 dosis fraccionadas en un lapso de 6 semanas $^{7}$. Actualmente existe controversia sobre el uso de radioterapia como tratamiento primario en estadios tempranos, pero el limitado número de casos en la literatura hace difícil análisis estadísticos significativos $^{8}$. La quimioterapia usualmente es considerada en estadios avanzados como tratamiento posoperatorio adyuvante a radioterapia para radiosensibilizar las características agresivas de la neoplasia como diseminación extracapsular². También hay estudios que consideran quimioterapia como tratamiento definitivo, con tasas de supervivencia similares a la terapia estándar en cáncer avanzado, siendo las principales drogas utilizadas: cisplatino, carboplatino, fluoracilo, docetaxel y mitomicina. No obstante, los resultados aún son controversiales?.

El pronóstico a cinco años varía entre $80 \%$ y $100 \%$ en estadios I y II, y desde $50 \%$ a $20 \%$ en estadios III y IV, Io que refuerza la importancia del diagnóstico temprano. Los factores pronósticos para carcinoma escamoso del conducto auditivo externo son estadio TNM, erosión óseo del CAE, márgenes quirúrgicos positivos, invasión locorregional extratemporal (parótida, cervical), compromiso en oído medio y presencia de parálisis de nervio facial ${ }^{1}$. Los tumores que se extienden a región preauricular 0 anterior tienen mejor pronóstico que aquellos que se extienden posterior medial e inferiormente ${ }^{10}$. La recurrencia es alta incluso después de resección curativa de la tumoración, y continúa siendo la principal causa de mortalidad en pacientes con carcinoma escamoso. Se reporta tasas de $23 \%$ a $63,8 \%$ en estadios avanzados, y de $5 \%$ a $19 \%$ en estadios tempranos ${ }^{8}$. Por ello, el seguimiento debe realizarse inicialmente cada 3-6 meses dentro de los 2 primeros años, cada 6 meses hasta los 5 años, luego anualmente?

\section{BIBLIOGRAFÍA}

1. Ouaz K, Robier A, Lescanne E, Bobillier C, Moriniere $S$, Baknos D. Cancer of the external auditory canal. Eur Ann Otorhinolaryngol Head Neck Dis 2013/07/13 ed. 2013;130(4):17582.

2. GidLEY PW. Managing malignancies of the external auditory canal. Expert Rev Anticancer Ther 2009/09/19 ed. 2009; 9(9): 1277-82.

3. Fleiner F, Jumah M, Goktas 0 . Cancer of the external auditory canal-diagnostic and treatment. Indian J Otolaryngol Head Neck Surg 2009/12/01 ed. 2009; 61(4): 270-4.

4. Lobo D, Llorente JL, Suárez C. Squamous cell carcinoma of the external auditory canal. Skull Base 2008/11/04 ed. 2008; 18(3): 16772.

5. Arriaga M, Curtin H, Takahashi H, Hirsch BE, Kamerer DB. Staging proposal for external auditory meatus carcinoma based on preoperative clinical examination and computed tomography findings. Ann Otol Rhinol Laryngol 1990/09/01 ed. 1990; 99(9 Pt 1): 714-21.

6. Moody SA, Hirsch BE, Myers EN. Squamous cell carcinoma of the external auditory canal: an evaluation of a staging system. Am J Otol 2000/07/27 ed. 2000; 21(4): 582-8.

7. Leong SC, Youssef A, Lesser TH. Squamous cell carcinoma of the temporal bone: outcomes of radical surgery and postoperative radiotherapy. Laryngoscope 2013/04/05 ed. 2013; 123(10): 2442-8.

8. Xie B, Zhang T, Dal C. Survival outcomes of patients with temporal bone squamous cell carcinoma with different invasion patterns. Head Neck 2013/12/19 ed. 2013.

9. Bacciu A, Clemente ia, Piccirillo e, Ferrari S, Sanna M. Guidelines for treating temporal bone 
carcinoma based on long-term outcomes. Otol Neurotol 2013/03/20 ed. 2013; 34(5): 898-907.

10. Takenaka Y, Cho H, Nakahara S, Yamamoto Y, Yasui $\mathrm{T}$, Inohara $\mathrm{H}$. Chemoradiation therapy for squamous cell carcinoma of the external auditory canal: A meta-analysis. Head Neck 2014/04/03 ed. 2014.
11. Mazzoni A, Danesi G, Zanoletti E. Primary squamous cell carcinoma of the external auditory canal: surgical treatment and long-term outcomes. Acta Otorhinolaryngol Ital 2014/05/21 ed. 2014; 34(2): 129-37. 